\title{
Practice, politics, and possibilities
}

Martin Marshall

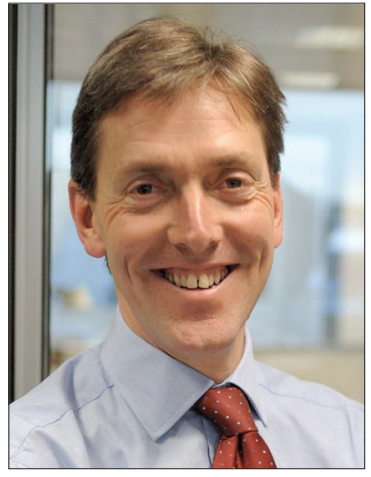

In 1501 , at the tender age of 26 , a sculptor, painter, architect, and poet called Michelangelo Simoni was asked by a Florentine guild to create a colossal statue portraying a symbol of Florentine freedom. The statue was to be given pride of place in the Piazza della Signoria in front of the Palazzo Vecchio. It is said that the young artist gazed on the massive block of white marble from the Carrara quarries in Tuscany and said quietly 'I see possibilities'. And what possibilities! Before he had even picked up his tools, and 4 years before the work was completed, an image of one of the greatest sculptures of all time, the Statue of David, was clear in his mind.

Our responsibility as members of a respected speciality within an influential profession must be to see 'possibilities', to look at what we have now, to imagine a masterpiece and then to sculpt.

In this lecture I am going to explore just how close our speciality is to a masterpiece. I am going to describe my view that while we have achieved an enormous amount, there is still much to do. And there are times when it feels like we are not making sufficient progress, or even have a clear vision of what we are trying to achieve. I am going to suggest that in order to make progress we should be less inclined to think within the boundaries of our discipline and more inclined to look outwards. I am going to suggest that we must think not only about our traditional role as doctors helping to care for patients, but about the role of general practice within our local communities and as part of a wider health and social care system.

I will attempt to address this ambitious remit by exploring three questions; First, is general practice in trouble? Second, what is the unique contribution that general practice should be making to improving people's lives, their health, and their health care?
And third, how can general practice ensure that this contribution is optimised?

\section{Is general practice in trouble?}

The discipline of general practice has developed at a truly remarkable pace in the 56 years since the Foundation of the Royal College of General Practitioners (RCGP). Humour me while I pretend that there is a single aggregated measure of the success of a discipline. And humour me even further while I plot this measure against time, starting in the early part of the 19th century when Loudon claims the discipline first emerged ${ }^{1}$ to the end of the 20th century. I think we would see a dramatic change in gradient in the mid-to-late 1950s after the establishment of the College. In part this would reflect the relatively slow rate of progress for the first 100 years of our speciality, hampered by the heterogeneous nature of general practice. But mostly I suspect it relates to the remarkable achievements of the leaders of our discipline, not just the national leaders whose portraits adorn the walls of the RCGP in Princes Gate but more importantly individual clinicians on the ground inspired by a sense of purpose and pride to serve their patients and their communities for decades. People who quite probably don't spend too much time thinking about where they fit into the wider system, they just get on with their job. These are the people on whom the reputation of general practice has been built.

What remarkable achievements we have seen. In so many areas it has been GPs, the very people who Lord Moran famously claimed had fallen off the medical career ladder, ${ }^{2}$ who have led the medical profession.

M Marshall, BSc, MSc, MD, FRCP, FFPH, FRCGP, CBE, clinical director, The Health Foundation, London. This text is based on the James Mackenzie Lecture delivered at the Annual General Meeting of the Royal College of General Practitioners, London, on 14 November 2008.

Address for correspondence

Professor Martin Marshall, The Health Foundation,

90 Long Acre, London, WC2E 9RA.

E-mail: Martin.Marshall@health.org.uk

Submitted: 13 February 2009; Editor's response: 20 February 2009; final acceptance: 27 February 2009. (c)British Journal of General Practice.

This is a full-length article of an abridged version published in print and originally published online first on 12 Mar 2009. Cite this version as: Br J Gen Pract 2009 DOI: 10.3399/bjgp09X420266 (abridged text, in print: Br J Gen Pract 2009; 59: 605-612). 
It was GPs who first professionalised medical education, who explicitly defined standards of training, who saw teaching the next generation as something only the best clinicians working in the best organisations should do, who established teaching as an earned privilege rather than a right. $^{3}$ And 30 years later most of the rest of the profession is only just thinking about catching up.

It was GPs who were first to describe a more strategic approach to the quality and standards agenda, who had the foresight to launch improvement campaigns in the form of the Quality Initiative in $1983,{ }^{4}$ who established a blueprint for standards of excellence with the development of Fellowship by Assessment in $1989^{5}$ and an impressive range of practice and team-based assessment and improvement processes over the last 15 years. And now this systematic approach to improvement is suddenly in vogue for the whole of the health service.

It was GPs who first recognised the importance of developing a true partnership with patients and the public and established mechanisms within the College and within individual practices to start developing this partnership. ${ }^{6}$ And 20 years later other parts of the profession and the health service are building on our achievements.

I could go on but I won't. I won't because humility is such an attractive characteristic but also because there is another story. The story of our collective failures. Of course it is important to celebrate success but it is also dangerous if we close our ears to criticisms of general practice. Many of these criticisms are far from new. For example the Collings report of 1950, which described the conditions in some practices as 'bad enough to change a good doctor into a bad one within a very short time'. ' Or Honigsbaum in 1972 who described the 'weakness, negligence and failure' of general practice. ${ }^{8}$

But while the criticisms are not new, I wonder if they are becoming more public and more widespread. It is very easy to be defensive when we read David Aaronovitch in the Times saying '... The "holistic" approach, is, in fact, code for "inexpert" ... I tend to use my GP's practice as a way of getting referral to specialists and accessing prescriptions that I have already decided that I need ... Cradle-tograve health care is as realistic as Dr Finlay's Casebook. We need specialists'. ${ }^{9}$ Or when we read Barbara Gunnell, Associate Editor of the New Statesman in the Observer saying '... no body loves GPs since they became overpaid and decided to work banking hours'. ${ }^{10}$

Comments such as these are so often poorly informed and certainly don't reflect the views of most of our patients - the opinions that really matter. And yet we mustn't fool ourselves. These criticisms, however few numerically, can be important politically; they can have a disproportionate impact on our collective reputation. They are made by the chattering classes, a group with great political influence whose support is key to sustaining the $\mathrm{NHS}$, they are listened to by policy makers and by politicians. They help to create an environment in which it is acceptable to question something that was previously either taken for granted or actively admired.

I use my dad as a yard stick. He has no political bias or prejudice, he is a regular user of his local practice as he gets older and is pleased with the service that he gets. And yet a few months ago he said to me that everyone seemed to be criticising general practice and he asked what was going on.

I think we dismiss these criticisms at our peril because unfounded criticisms quickly get mixed up with ones that perhaps have some basis, creating an impression of failure and a collective defensiveness. I think we need to be more open about the unacceptable face of general practice. I think we need to confront our deficiencies. So, to balance my celebration of our successes, allow me to be critical.

Perhaps our greatest failure, recognised for decades, has been our inability, or perhaps unwillingness, to deal with what we euphemistically call 'poor performance' - the 'rump' of general practice to use more provocative terms. In my role as a clinician and someone committed to improvement I have been exposed to some of the best of general practice. But I have also been on local performance panels and have worked in government and here I have been exposed to what I can only hope is the very worst. And I'm not talking about GPs who only achieve $50 \%$ immunisation rates or who are the recipients of numerous complaints. I'm not even talking about GPs who can't tell you the risks of poorly controlled diabetes, although I have sat in despair in front of doctors like this. I'm talking about a GP who didn't have chair for his patient to sit down on because he said it slowed down his consultation rate. I'm talking about a GP who was found to be reusing unwashed disposable specula.

These examples happened within the last 5 years. They may be rare but they reflect badly on all of us.

It is difficult to find someone who says we should just ignore these problems, although the most common response that I hear is that poor performance happens on such a small scale that we shouldn't let it distract us from more important matters. It is someone else's problem. Perhaps we should remind ourselves that our College was founded 'to encourage, foster and maintain the 
highest possible standards of general medical practice'."1 Note, not 'pockets of the highest possible standards' or even 'the highest possible standards among our members'. I'm not sure that our long-term aims of excellence across our speciality will be served if we only look after the interests of active members of the College, the people who by definition occupy the front end of the performance curve.

Our problems are not just ones of commission by a few individuals. There are also problems of omission by all of us, ignoring health and social care issues, which general practice is uniquely placed to address but has largely failed to act upon. These are the issues that require us to be more able to see and act upon the bigger picture of our role in our communities, the wider health system, and in society. Let me describe two examples:

- Teenage pregnancies: the teenage pregnancy rate in the UK is twice as high as in Germany, three times as high as in France, and six times as high as in the Netherlands. One-third of pregnant teenagers receive inadequate antenatal care. ${ }^{12}$ To what extent are GPs working with others to address these challenges? Are we optimising our privileged access to these children before they get pregnant?

- Access to GPs: there are $81 \%$ more GPs per 100000 patients in wealthy South Cambridgeshire than in deprived Doncaster West. ${ }^{13}$ This differential has persisted despite many attempts over the years to reduce it. Given the evidence of an association between GP distribution and health outcomes, ${ }^{13}$ what are we doing collectively to ameliorate it? Are we working with deaneries and PCTs to make these areas more attractive to new GPs? Are we thinking innovatively about new models of working that would allow each and every one of us to work for some of the time in these communities?

Some of our leaders have understood the importance of these challenges and the braver ones have fired warning shots across the bows of our specialty. Thirty years ago Donald Irvine said '... a glance at our track record shows why the public is sceptical of our attempts to apply consensus criteria to all practitioners'. ${ }^{14}$ Twenty-eight years ago Denis Pereira Gray made it clear that 'bad general practice could still drive out good general practice'. ${ }^{15}$ And 10 years ago Martin Roland claimed 'It is quite possible to visualise a scenario where the profession has failed to demonstrate it can improve the quality of care, where doctors come under increasing external control'. ${ }^{16}$
What can I say? Aren't we now close to the position that these commentators feared? It seems to me that as a speciality we are no longer leading the profession in the field of quality. Certainly as far as professional bodies are concerned, we are no longer in the vanguard. The Royal College of Psychiatrists, the Royal College of Physicians, even the Royal College of Surgeons, are doing more innovative work in the field of improvement than our College. We are still using too much of the language and the methods of the 1980s and 1990s. We still see standards as the main manifestation of quality, despite the evidence from outside the health sector that a more dynamic approach to continuous improvement is more likely to achieve results. ${ }^{17} \mathrm{We}$ still see a strong focus on training to manage patients and not on the ability of professionals to manage the environment in which they are working. We don't have a clear strategy or a commitment to the emerging science of quality improvement.

So I think there is a real risk that collectively we are not stepping up to the mark. What should be isolated criticisms could turn into a fundamental challenge to our future. The traditional model of general practice is under threat; what we have grown to know and love is being shaken up. We are seeing the corporatisation of small independent businesses. And this process is all the more scary for being part of bigger societal threat.

This challenge is well described in The Gods That Failed by Larry Elliot and Dan Atkinson. ${ }^{18}$ They make it clear that GPs aren't the only respected profession who are no longer being allowed to quietly get on with the same job that their predecessors did. They give the example of solicitors. The liberalisation of the legal system has led to legal advice booths in supermarkets, to the merger of family firms, to young solicitors being employed by large multinationals or moving into city banks to be rewarded with another Ferrari or another holiday on Mustique. Does the story sound familiar? GP partners talking about selling out to large corporations, aspiring young GPs employed by these companies at a lower salary, or turning to careers outside medicine. I don't think that GPs should be any more paranoid than other professional groups in today's society. The threat is not personal, but it is real.

So, it feels to many as if our much cherished speciality is under threat. Some people are asking whether the days of the generalist are numbered. The battleground for GPs used to be about our credibility with our specialist colleagues. Now it is increasingly about our credibility with society. Wise heads will tell us not to worry, the demise of general practice has been oft-predicted. They quote Rosemary Stevens, the American sociologist who once commented, 'If 
the GP did not exist he (or someone like him) would have to be invented'. ${ }^{19}$ Students of history will describe other times in the past when fundamental changes were proposed, but in spite of the prophets of doom general practice evolved, survived, and even came out stronger. ${ }^{20}$

For example when in the 1920s Dawson provoked the ire of the many single-handed GPs when he recommended the development of health centres. Or in 1946 when the Medical Practices Committee was established to regulate the distribution of GPs amid wails of anguish that it challenged the basic human rights of a doctor to practise where they wished. Or in 1984 when the government placed limits on the freedom to prescribe, a move that was described by the BMA as 'one of the biggest changes in the NHS since its introduction'. Or, dare I say, to the 2008 Darzi recommendations about GP-led health centres, ${ }^{21}$ a recommendation which in principle, to my mind, is just a reiteration of the Dawson recommendations from the 1920s. Progress goes in circles. Innovation is, indeed, a function of amnesia.

General practice has a long track record of crying foul and then simply carrying on delivering the goods. Rudolph Klein, in his usual elegant and understated way, has remarked that so often 'the degree of hostility appears - in retrospect, at least - to be disproportionate to the causes'20

So let me summarise my answer to the first question, is general practice in trouble? My view is not yet, although I recognise that some of our colleagues operating outside the seductive world of professional politics say it feels pretty bad. But I do think we could easily drift into a real crisis, one in which the very existence of everything that we cherish is threatened. We need to remember that however important we in this room know general practice is to patients, to communities, and to the health system, its continuing existence in the UK is not inevitable. There are other models of healthcare delivery and there are countries that used to have a strong system of general practice but do no longer. And if the widespread model that we know is damaged or destroyed, the world would go on - a poorer place but it would continue.

To prevent this, I wonder if it would be helpful to step back and address my second question; what is the unique contribution that general practice should be making to improving people's health and health care?

\section{What is general practice's unique contribution?}

At the heart of this question lies the importance of developing a shared understanding of the role of general practice in a modern health system. I frame it in this way purposely - while there are some things about general practice that don't and shouldn't change, the model of general practice that fitted 1950s or 1980s society and health system is not necessarily the model that will fit current times. And society is changing at a dramatic pace. In Future Shock ${ }^{22}$ Alvin Toffler describes how we travel more and faster; we relocate more frequently to new residences, which are built and torn down more quickly; we contact more people and have shorter relationships with them; we are faced with an array of choices among styles and products which were unheard of the previous year and may well be obsolete or forgotten by the next. $\mathrm{He}$ says that novelty, transience, diversity, and acceleration are what modern society is about. General practice can't afford to stand still in the face of these changes. We might have demonstrated our ability to evolve but I am not convinced that we are reflecting the pace of change described by Toffler. And too often our response is reactive rather than proactive.

So, what is general practice and what it is for? Many, perhaps too many, people have had a go at defining our discipline and our role. Perhaps we could be criticised for being too introspective and I for one am sceptical about the benefits of attempting to produce a universally agreed definition. Personally I rather like the approach of the so-called Black Pope, the Superior General of the Jesuits, who was not interested in the purity of Vatican doctrine but was very interested in how the teachings of the church were interpreted by the common people.

So I don't want to add to the long list of definitions of our discipline. I really don't want to. But the definitions that are taught in our training, ${ }^{23}$ around which we have shaped our identity, concern me when I revisit them. They all have a go at defining what's important about general practice, at elucidating our core values. But when I talk to the young GPs or registrars in my practice and more widely about these values, they get uncomfortable. They say to me that these might be good values for 'your' generation (they know how to hit me where it hurts), they might even be ok now for practices serving stable communities, but however noble they are, they don't reflect the realities of modern life for us. They tell me that they don't want their lives organised around on-call commitments, or to work for 10 or 12 hours a day. They don't want to be tied to the same practice for the whole of their career. They don't want their professional life to dominate their personal life. They don't want to have the same risk of alcoholism, depression, and family breakdown as they perceive were experienced by earlier generations of doctors. 
That started me thinking; what use are values that an increasing number of our speciality, particularly our successors, the next generation, do not even want to aspire to? Of course values should be aspirational but like the Jesuit's approach to doctrine, they need to be liveable too. So do we need to revisit our values and define them in a way that focuses not only on what is fundamentally important but also on what is deliverable? Let me have a go. I suggest that there could be only three core values that should define our discipline and around which we should design what we do.

First, all GPs should be committed to being excellent medical generalists. By this, I mean that the foundation for being a high quality GP must be being a competent medical practitioner, someone who practises safely, who is up to date with the evidence, who knows when to act, when to wait, and when to refer. Someone who has the well-honed clinical sixth sense. Without this sophisticated clinical competence - an area that we have tended to take for granted as we focus on the psychosocial dimension of our discipline - we would have no credibility with our patients.

Second, all GPs must be committed to whole person care. They must be able to make competent medical diagnoses and offer care, advice, or treatment in the context of the psychological, social, and spiritual factors which we know influence our patients and the ways that they present problems. That is, we must practise in the real world, not in an artificial world created by medical reductionists. This is perhaps the key issue that defines us as different from many specialists who are more able than us to achieve their objectives in a context-free environment.

Third, all GPs must be committed advocates on behalf of their patients and their communities. They must be willing to act as the patient's guide through the morass of information available to them and the complexity of the health system beyond the GPs consulting room, help them deal with the uncertainties and complexities of their lives, fight for them when they are unable to fight for themselves. They must, in John Berger's words, 'ease people's lives', ${ }^{24}$ or as described slightly less eloquently by one of my less fortunate patients, 'Just remember $\mathrm{Dr}$ Marshall, my life is like a swimming pool full of sewage and your job is push me up into the shallow end'.

These are what I see as being the core values of general practice in the future. They aren't innovative (which should come as a relief) and they are perhaps as notable for what they exclude as what they include. You will notice that I haven't mentioned some of the values that general practice has traditionally held dear - a focus on families, longitudinal and personal continuity, first-line care for example. Focusing on my three core values doesn't mean that these traditional 'values' are unimportant.

Of course providing care for families and understanding the impact of family dynamics on individuals is important but we can't escape the fact that families are less central to our society than they were decades ago and many of our patients aren't or don't feel part of a family unit. Many in my practice in Lambeth, South London, don't feel part of any social unit. That is one of the reasons they come to see me.

Of course interpersonal or relational continuity is important for some people at some times of their lives, but a combination of patient and health professional mobility, European legislation, and lifestyle choices mean that delivering interpersonal continuity for most people most of the time is increasingly difficult and GPs are having to rely more on informational continuity, using medical records, than they have in the past.

Of course first-line care, the gatekeeper function, is important but where do we draw the line between our role in managing demand - a key rationale for the gatekeeping function - and our professional responsibility to be patient-centred, not to act as a brick wall between patients and what many of them are quite sure best meets their needs?

So continuity, family care, and first-line care must not be lost or designed out of the system, but perhaps can be better seen as 'tactics' that help deliver the three core values, rather than as core values in themselves. Tactics that should be used whenever appropriate but not essential elements of general practice, which if you aren't able to use then you would end up being judged by your peers to be 'not a proper GP'.

So, looking after families helps us deliver the core value of holistic care, particularly the social component, but we need to find alternative ways of doing so for the increasing number of sociallyisolated patients. Continuity helps us to deliver the core value of advocacy but we need to find alternative ways of doing it when a range of factors conspire against us. First-line care allows us to protect patients from unnecessary medical interventions and to manage limited resources effectively, but GPs know how difficult it is to achieve a balance between their often conflicting responsibilities to patients, to populations, and to the health system, and perhaps we need to explore other ways of delivering these imperatives.

You could criticise this approach for being too pragmatic - backing off from what is important because it's too difficult to deliver. Perhaps I'm inadvertently raising the blood pressure of those 
readers who have built their identity around the traditional model of general practice. The social campaigners among you might say we should lead the fight against the wrongs of modern society. But I think it's good to be pragmatic and I am fairly sure that the social trends that I have described will have an even greater influence on modern society in the future and therefore a greater threat to an unreconstructed model of general practice. A bit of pragmatism may prevent us losing all.

What are the implications of this conceptualisation of general practice? I think we should think about general practice's contribution to the health system of the future in terms of the core values of excellent medical generalism, whole person medicine, and patient advocacy. The issues that tend to dominate discussions about our future - like should we be independent or employed; should we work in discrete small teams, as part of federations or integrated with acute services; should we locate our practices in supermarkets or sports centres; should we work alongside specialists or separated from them - should we no longer be seen as defining features of general practice or as battle grounds to defend. They all become second order issues, whose significance lies in the extent to which they facilitate or block the implementation of the three core values. And the extent to which they facilitate or block may vary between individual doctors, practices, and geographical locations. As long as we build our identity around the core values, then this variation would not matter.

So I think that this approach of focusing on our core contribution to the health system and to wider society could contribute to securing a bright future for general practice. In the third and final section of this presentation, I want to explore how we could go about conveying and delivering this vision.

\section{How can general practice ensure that its contribution is optimised?}

I think that the forces that I have described acting against medical generalism are significant ones. I am not convinced that generalism will survive the next half century if we are passive but I am absolutely sure that it must. I think we need to be actively defending our speciality, fighting for it and, if you'll excuse my English, fighting clever - cleverer than we have done in the past.

Rather than complaining about our critics we need to take them on. Rather than blaming people for not understanding us, we need to critically examine our own ability to get our message about generalism and general practice across. Rather than complaining that there is a Machiavellian plot to destroy general practice, we need to enter robust and informed discussions about the pros and cons of the current model. Rather than revelling in our small business ethos we need to recognise that collectively general practice could be immensely powerful. Just look at our economic clout. Taking into account just the spending on GP contracts and prescribing, the expenditure on general practice in 2007 in the UK was in excess of $£ 16$ billion (Department of Health Statistics Unit, Personal communication, 2008). If this were the GDP of a country, the International Monetary Fund would rank general practice 80th out of the 179 nations in the world. £16 billion is twice the annual turnover of Marks and Spencer. General practice is big but it doesn't always think big, it doesn't exercise its potential collective influence.

The problem is, I propose, that collectively we've not been good at playing the political game. And by political I am referring to the terms 'politics' and 'politic' in their broadest sense. The Oxford English Dictionary tells us that politics is 'the management of relationships involving power; any activity concerned with gaining one's own ends' and that politic means 'wise or shrewd'. My argument is that the challenges that general practice is facing may not be of our own making but are within our power to address, if as a profession we are willing to operate in a politically sophisticated way. The current situation is not a bad reflection on individuals, many of who have fought battles over the years, with notable successes. But overall we are too often still finding ourselves fighting the same battles. Sometimes we aren't collectively sufficiently shrewd.

Peter Davies, a GP from Illingworth reflected on this in a letter to this journal last year. ${ }^{25} \mathrm{He}$ describes how GPs are uniquely placed to recognise both the ills and the strengths of the communities that they serve. He says that 'this country needs a powerful and assertive medical profession to draw attention to the many problems within its society. Maybe our role as doctors should be more political than it currently is'. Maybe indeed.

You won't be surprised to hear that Julian Tudor Hart espouses similar views, although using a little more robust language. In his book The Political Economy of Health Care: a Clinical Perspective ${ }^{26}$ he complains about 'the political illiteracy of most doctors'. Only by recognising and engaging with the politics can what Tudor Hart describes as the many doctors who are 'arrogant, paternalistic and condescending' really 'democratise their work'. Julian doesn't hold back the punches, does he? He is enormously frustrated by the political apathy of so many people.

Surprisingly, Tudor Hart's view is very much in line with that of the Conservative politician Keith Joseph, who, in 1973, said: 'Doctors can be remarkably 
selective about choosing the ills they see worthy of treatment. No one can see better than doctors the needs of the public and the shortcomings of the service. I am not aware that there has been steady, powerful medical pressure to remedy the really worst shortcomings' ${ }^{20}$

So, a consensus across the political divide that the medical profession - and I would argue GPs in particular - do not always exercise their influence in the most positive of ways. I agree with this view. I think that as GPs we need to stop wearing our unwillingness to engage with policy and with politics as badge of honour. I think we should stop dismissing politicians and policy makers for some of their obvious deficiencies. I don't think we can afford the luxury of splendid isolation. All of us need to develop our collective political nous at a national level and at a local level. Only then will we achieve real change.

So, my thesis is that as a discipline general practice has not managed to persuade others that what it does is essential. We have been insufficiently political (that is, willing to exercise influence) and politic (that is, wise). If we are to preserve the fundamental values that general practice brings to the health system and to wider society then we need to ask ourselves a simple strategic question; how do we best influence those who matter in order to keep general practice at the heart of the health system? Our challenge is to find a way of communicating our importance, of selling our discipline.

Here I think we need to look outside our established body of knowledge in the way that our predecessors did in the 1960s when they turned to the academic field of education to find new ways of teaching trainees. ${ }^{3}$ Expertise in the area of communication, of changing mindsets and behaviours, lies in the field of marketing, particularly social marketing, underpinned by the science of cognitive psychology.

The concept of social marketing is an idea developed by Philip Kotler and Gerald Zaltman in the early 1970s. ${ }^{27}$ It is about 'selling' for social good rather than for profit. It emphasises the importance of values, of understanding the target audience in their social context, of working with them to change their thinking and their behaviours rather than doing something to them. The approach has been used successfully in a number of different areas including public health campaigns, with pioneering programmes in Australia such as 'Quit' to stop smoking and 'Sunsmart' to reduce the risk of skin cancer. There is a growing body of research evidence that social marketing works. ${ }^{28}$

Social marketing techniques have been used to turn around major institutions in the ways that I think might have lessons for general practice. Let me give you two examples.

First, the British Library. Ten years ago the British Library was being left behind by the Googles and the Amazons of the electronic world. Cardex's and interlibrary loans just didn't seem to fit into an electronic society. The British Library was inward looking, elite, and bound by its walls. Its vision was to preserve books. Now, following sophisticated marketing interventions, the British Library is an outward looking, global organisation that sees itself as a collaborative co-producer of knowledge. It focuses on people rather than books. It is a completely different organisation, looking forward to a bright future.

My second example is cricket. Ten years ago it was a game with limited appeal. It was watched by people in deck chairs who broke their quiet naps with occasional cups of tea. And after 5 days the contest often ended in a draw. The whole thing was eccentric, quaint but hardly compatible with modern life. But then marketing experts got involved. They introduced the short game, put players in coloured pyjamas, developed new viewing technologies and ways of explaining the complexities of game to the uninitiated, emphasised the personalities of the players and the colour of the international game, and even encouraged a bit of fun among the spectators. A minority sport has been turned into an international obsession, heroes have been created, youngsters who wouldn't have been seen dead at a cricket match are now queuing up months in advance to buy tickets. Cricket too has a bright future; a different one but a bright one.

How is this relevant to general practice? In my roles as a researcher, policy maker, and now in the charitable sector at the Health Foundation, I've had to think beyond how to influence individual patients sitting with me in the consulting room (something that GPs are highly effective at) to thinking about a wider influencing role. In attempting to achieve this, I've been privileged to work with some remarkable experts in the field of communications and marketing. I've been talking to them about whether general practice could or should be seen as an entity that needs to be 'sold'. We've had interesting and challenging conversations and I would like to share them with you because I do wonder if there are ideas here which could be used to achieve our aim of ensuring a bright future for general practice.

The first question that they wanted to know was what is your product, your message, your, to use the jargon, Unique Selling Point? I said well, we've got this thing called general practice which is a long-standing part of a system that provides health care for people in the UK. We know that it enables 
other aspects of the health system to function effectively, that it is very popular with most of the people who use it, that it achieves excellent results, and it is essential to ensure that taxes are used efficiently.

Their response was, of course, why on earth would you need to 'sell' a product as good as that? Most of our clients would die to have the opportunity to sell something that had such undiluted benefits. So I explained that, first, not everyone thinks that it is such an unequivocal good (and many of those who don't are politically powerful) and those who like it and trust it do so in a passive way. They would miss it if it wasn't there but they don't think it is under threat, they take it for granted. And those who don't like it either don't understand what benefits it provides, or focus on its deficiencies. So while they rarely openly attack it, they chip away and slowly but surely discredit and damage it.

OK, my new marketing friends said, we can see your problem. You suffer from poor brand awareness and weak benefits appreciation. You have failed to frame your benefits on your own terms and in ways that others understand. I wasn't entirely sure what they meant but it sounded like a small step forward.

They then asked me how the product, general practice, had been marketed in the past. I must say that this stumped me. I explained that we didn't really see general practice in this way. Indeed, I said that most GPs would be pretty sceptical about that kind of language. I said we relied on providing a good service at a local level and the trust and popularity that ensued from this. I explained that at a national level we had traditionally responded to specific threats or challenges in a rather reactive way and that we tried to use hard scientific evidence supporting the benefits of general practice whenever we could, although we hadn't found it particularly easy to marshall the evidence and present it in a compelling way.

This was when they sighed, an expression of exasperation at my naivety. You have three basic problems they said. First, you have to find a way of getting over your scepticism about marketing. If you want to operate effectively in the modern world then utilising the behavioural sciences that underpin marketing should be a mainstream activity. Second, influencing in modern society is not something that happens by accident. You need to be strategic and proactive about it. Third, and most importantly, influencing is not about scientific evidence, it is about feelings and impressions.

Of course, as far as the third issue is concerned, GPs of all people know that they are right. Aristotle recognised this when he said in his book Rhetoric that if we want to move people then we need to be concerned with their 'pathos', that is, their emotions. Even the most accomplished hardedged scientists achieve success through intuition as much as through the application of logic. Einstein once said 'when I examine myself and my methods of thought, I come to the conclusion that the gift of fantasy has meant more to me than my talent for absorbing positive knowledge'. And James Watson turned to Francis Crick after 2 years of testing flawed models for DNA and said of the double helix, which came out of the blue, 'this is too pretty not to be it'.

Language and aesthetics are key to influencing. If Churchill had said 'the RAF has done a lot for us' then it probably wouldn't have had the same impact as 'Never did so many owe so much to so few'. If the famous Rolls Royce advert had described 'a well sound-proofed car' then it probably wouldn't have been as successful as the line 'at 60 miles an hour the loudest noise you hear comes from the electric clock'. A claim that apparently upset the clock engineers greatly.

Harry Frankfurt described the importance of communication rather beautifully in his learned tome entitled On Bullshit. ${ }^{29}$ Frankfurt is emeritus professor of moral philosophy at Princeton University. He describes how everything that we say creates an impression and that this impression is as important as the content of what we say. He describes an American orator going on bombastically about 'our great and blessed country, who's founding fathers under divine guidance created a new beginning for mankind'. Frankfurt says that while this is clearly humbug, the orator isn't lying. And he doesn't really care whether his audience thinks that the country is great, that the Founding Fathers had divine guidance or whether they really did create a new beginning for all of us. What the orator is trying to do is to create a certain impression of himself. What he cares about is what people think of him. He wants them to think of him as a patriot, as someone who thinks deeply, who is both proud and humble and so on. What matters is the impression left by our communication, as much as the content.

That is why stories, narratives, have such a powerful influence. They leave an impression. The marketing experts told me that if our critics think that general practice is easy, that anyone could do it, then telling stories to illustrate the complexity of providing front-line care to patients would speak infinitely louder than statistics. They asked me to give some examples of narratives from my own practice, so I told them two stories.

It was the early 1990s and I was not so long out of my hospital jobs, bright eyed and bushy tailed 
about the potential of biomedical science to make a difference to my patients. I was looking after a lady who had a significant and long-standing clinical depression which was largely the result of an unhappy marriage in which she was emotionally abused. Her previous GP had tried but failed to help her and I was very proud when I persuaded her to start Prozac $^{\circledR}$. I followed her up closely and her response was truly an accolade to modern therapeutics. She told me that she suffered a few side effects for the first couple of weeks, starting feeling better after a month on treatment, felt happier than she had ever done by 4 months, and sustained the benefits after we stopped the treatment after 6 months. Classic medicine I remember remarking slightly smugly to a medical student studying in my practice. But about 18 months later the patient came back to me with a rather sheepish smile on her face. She said, 'Dr Marshall, I felt that I just had to own up to never taking the Prozac that you prescribed for me. The way that I figured it, the depression wasn't my problem, it was my husband's, who was always so miserable. So I put the Prozac tablets into his morning coffee. He complained of a few side effects in the early days but he got better pretty quickly and now we've got a better relationship than we've ever had'.

Then I told them about a guy in his early 20 s who I saw in my practice in Lambeth just a few months ago. He was a drug addict, on antidepressants, and had a long history of suicide attempts, usually overdosing on his antidepressants. He wanted a repeat prescription and as I gave it to him I explained why we only gave a week's supply at a time. He said to me that he knew my intentions were good but that they were a bit pointless. He described how he was one of a group of eight young people, all with similar mental health problems, all on weekly prescriptions of antidepressants from our practice. They lived in council flats near the practice and when things looked bleak they'd get together around a kitchen table, put their medications in a pile in the centre of the table and draw straws to see who's turn it was to take the overdose.

I explained to my marketing friends that I had learnt a lot from these encounters. I learnt that life is more complex than the medical text books would have us believe. I learnt not to force people into doing things that they didn't believe in. I learnt to listen and observe and question. I learnt about the importance of trust in facilitating disclosure and allowing challenge and how trust can develop quickly. And I learnt to say to policy makers 'QOF that if you can'!
The marketing people said what many others have said when l've told them these stories - 'people really don't understand the complexity of general practice'.

The final question my marketing friends asked me was 'who are your target audience?' Again I struggled. I rather lamely said, well, I guess it's the people with power and authority who influence or make health policy - politicians, policy makers, senior leaders in other branches of the medical profession. And of course the media. Wrong, they said (again). Why talk to the monkey when you can go straight to the organ grinder? It is your patients, local communities, the public that you need on your side. The media will champion the public (because owners and editors have to be commercial) and politicians will follow public opinion and media pressure (because they want to be re-elected). Influencing is not that difficult, it is about understanding and then framing the benefits to your target audiences.

Your main challenge, they said, is to turn your patients and communities from passive supporters to active champions. To people who will truly understand the benefits of having a health system based on high quality general practice. Who have thought about and rationalised the trade-offs that such a system brings - that their GP might not know as much as a cardiologist about rare rhythm disorders but they know more than that cardiologist about non-cardiac causes of dizziness, and they know more than enough cardiology to provide safe and effective care. That they might not have direct access to the latest neurological scanning investigations but they have a better idea than a radiologist about when a headache warrants a scan and when it doesn't.

They said you need patients and communities who will actively work in partnership with you to create a model of general practice that satisfies the three core aims of excellent medical generalism, whole person medicine, and patient advocacy. They said if you really believe in general practice then you need to mobilise your patients and communities to create the kind of social movement that abolished the slave trade and is now addressing global warming. You need to professionalise your approach to influencing and provide national coordination for local action. You need to be willing to use what the psychologist Robert Cialdini calls 'weapons of influence'. ${ }^{30}$

\section{Conclusion}

In conclusion, I would like to thank the College for the great honour of inviting me to give this year's James Mackenzie lecture. I suspect that if 
Mackenzie were sitting in the audience today he might have been a bit bemused by the concept of 'social marketing'. But as a man totally committed to general practice, with a sharp and enquiring mind, he certainly would have wanted to explore ways of preserving our discipline.

I would like to thank you for your attention. The behavioural sciences tell us lots of important things, not least that even the most stoic of us have an attention span of about 11 minutes. I am grateful to you for your forbearance.

I've tried to describe why, despite general practice's remarkable successes and its clear and uncontested benefits to patients, communities, and the health system, it is nevertheless under threat. I have tried to explain how we need to be more outward looking, more focused on our unique contribution and less distracted by battles that don't need to be fought. And l've suggested that we might benefit from looking outside our current knowledge base, and comfort zone, to the world of social marketing to get our message across.

I started by telling you about Michelangelo's statue of David. And I will finish with a confession. I told you a little white lie. Michelangelo didn't actually start the statue. A little known sculptor called Agostino di Duccio was actually originally commissioned by the Florentine Guild to undertake the work but for reasons that are lost in the mist of time, Michelangelo was asked to take over at an early stage. Who knows how it would have turned out if he had not been tapped on the shoulder. But I do know that there is a lesson for us. The current generation of GPs are being asked to take over where our predecessors left off. Our challenge, should we decide to accept it, is to help create a masterpiece.

\section{Competing interests}

The author has stated that there are none

\section{Acknowledgements}

I would like to thank all those who inspire and challenge me in my career - patients, mentors, professional colleagues, and most importantly, my wife, Susan.

\section{Discuss this article}

Contribute and read comments about this article on the Discussion Forum: http://www.rcgp.org.uk/bjgp-discuss

\section{REFERENCES}

1. Loudon I. Medical care and the general practitioner 1750-1850 Oxford: Clarendon Press, 1986.

2. Moran C. Evidence to the Royal Commission on doctors' and dentists' remuneration. London: HMSO, 1960.

3. Working Party of the Royal College of General Practitioners. The future general practitioner; learning and teaching. London: RCGP, 1972.

4. Irvine D. Quality of care in general practice: our outstanding problem. J R Coll Gen Pract 1983; 33: 521-523.

5. Royal College of General Practitioners. Fellowship by assessment. Occasional Paper 50. London: RCGP, 1990.

6. Pritchard P. Partnership with patients; a practical guide to starting a patient participation group. London: RCGP, 1993.

7. Collings SJ. General practice in England today: a reconnaissance. Lancet 1950; 1: 555-583.

8. Honigsbaum F. The division in British medicine: a history of the separation of general practice from hospital care 1911-1968. London: Kogan Page, 1979.

9. Aaronovitch D. Ignore GPs. Polyclinics are the future. Times 2008; 19 Feb: http://www.timesonline.co.uk/tol/comment/columnists/david_ aaronovitch/article3393128.ece (accessed 2 Mar 2009).

10. Gunnell B. Comment The Observer 2008: 29 June

11. Fry J, Lord Hunt of Fawley, Pinsent RJFH. A history of the Royal College of General Practitioners: the first 25 years. Lancaster: MTP, 1983.

12. Department of Health, Social Exclusion Unit. Teenage pregnancy. Cmnd 4342. London: Department of Health, 1999.

13. Hann M, Gravelle $H$. The maldistribution of general practitioners in England and Wales 1974-2003. Br J Gen Pract 2004; 54(509): 894-898.

14. Irvine D. The future of the College - 2. J R Coll Gen Pract 1978; 28(188): 146-153.

15. Pereira Gray DJ. Just a GP. Gale Memorial Lecture 1979. J R Coll Gen Pract 1980; 30(213): 231-239.

16. Roland M. Quality and efficiency: enemies or partners? James MacKenzie Lecture 1998. Br J Gen Pract 1999; 49(439): 140-143.

17. Langley GJ, Nolan KM, Nolan TW, et al. The improvement guide: a practical approach to enhancing organisational performance. San Francisco, CA: Jossey-Bass, 1996.

18. Elliot L, Atkinson D. The gods that failed: how blind faith in markets has cost us our future. London: Bodley Head, 2008.

19. Stevens R. Medical practice in modern England. New Haven, CT and London: Yale University Press, 1966.

20. Klein R. The new politics of the NHS. 5th edn. Oxford: Radcliffe Publishing, 2006.

21. Darzi A. Healthcare for London: better health, better healthcare. www.healthcareforlondon.nhs.uk/assets/Publications/Publicinformation-Leaflets/BetterHealthBetterHealthcare.pdf (accessed 2 Mar 2009).

22. Toffler A. Future shock. New York, NY: Random House, 1970.

23. Royal College of General Practitioners. What sort of doctor? London: RCGP, 1985.

24. Berger J, Mohr J. A fortunate man; the story of a country doctor. New York, NY: Holt, Rinehart and Winston, 1967.

25. Davies P. QOF. Br J Gen Pract 2007; 57(543): 836.

26. Tudor Hart J. The political economy of healthcare; a clinical perspective. Bristol: The Policy Press, 2007.

27. Zaltman G, Kotler P, Kaufman I. Creating social change. New York: Holt, Rinehart and Winston, 1972.

28. Kotler P, Roberto N, Lee N. Social marketing: improving the quality of life. Thousand Oaks, CA: Sage Publications, 2002.

29. Frankfurt H. On bullshit. Princeton, NJ: Princeton University Press, 2005.

30. Cialdini R. Influence; the psychology of persuasion. New York, NY: Collins, 2007. 